\title{
Linearity of the Atmospheric Response to North Atlantic SST and Sea Ice Anomalies
}

\author{
SÉBASTIEn ConiL* AND LAurent Z.-X. Li \\ Laboratoire de Météorologie Dynamique, Paris, France
}

(Manuscript received 3 February 2004, in final form 2 November 2004)

\begin{abstract}
The observations of the ocean-atmosphere-sea ice have recently revealed that the oceanic surfaces can have a subtle but significant impact on the atmospheric long-term fluctuations. Low-frequency variations and long-term trends of the North Atlantic atmospheric circulation have been partly related to particular SST and sea ice features. In this work, the influence of typical tripolar SST and dipolar sea ice anomalies in the North Atlantic-Arctic on the atmosphere is investigated. A large ensemble of AGCM simulations forced by three different anomalous boundary conditions (SST, sea ice, and SST + sea ice) are used. The linearity of the simulated response in the winter season is particularly assessed.

In these experiments, while the winter low-level temperature response is mainly symmetric about the sign of the forcing, the asymmetric part of the geopotential response is substantial. The sea ice forcing maintains a baroclinic response with a strong temperature anomaly in the vicinity of the forcing but with a weak vertical penetration. The SST maintains an NAO-like equivalent barotropic temperature and geopotential height response that extends throughout the troposphere. It is also shown that the combination of the two forcings is mainly linear for the low-level temperature and nonlinear for the geopotential height. While the SST forcing seems to be the main contributor to the total temperature and geopotential height responses, the sea ice forcing appears to introduce significant nonlinear perturbations.
\end{abstract}

\section{Introduction}

Recent analysis of the North Atlantic and Arctic Oceans' surface characteristics have revealed the existence of fluctuations of the sea surface temperature (SST) and sea ice at interannual and decadal time scales. The dominant mode of the SST variability in the North Atlantic Ocean has a well-known tripolar structure (Wallace et al. 1990; Deser and Blackmon 1993; Sutton and Allen 1997; Watanabe and Kimoto 2000; Da Costa and Colin de Verdiere 2002). In the Atlantic part of the Arctic, the sea ice concentration (SIC) variability is dominated by a dipole pattern around Greenland (Slonosky et al. 1997; Deser et al. 2000; Venegas and Mysak 2000). Deser et al. (2002) have examined the relationships between the SST and SIC variability in the Labrador Sea and North Atlantic Ocean. They have shown that above-normal sea ice conditions in the Labrador Sea are associated with below-normal SST in the subpolar Atlantic that can persist for nearly $3 \mathrm{yr}$.

\footnotetext{
* Current affiliation: Department of Atmospheric Sciences, University of California, Los Angeles, Los Angeles, California.

Corresponding author address: Sébastien Conil, Department of Atmospheric Sciences, University of California, Los Angeles, 405 Hilgard Ave., Los Angeles, CA 90095-1565. E-mail: conil@atmos.ucla.edu
}

Observational and modeling studies have given evidence that the atmospheric changes associated with the NAO are responsible for most of these oceanic surface variabilities at the interannual-decadal time scales (see the review of Visbeck et al. 2003).

Investigations of the ocean-atmosphere interactions in the North Atlantic-Arctic region have suggested that the local oceanic surface (SST and sea ice) changes may have noticeable impacts on the atmospheric circulation (Czaja and Frankignoul 2002; Rodwell and Folland 2002; Slonosky et al. 1997; Deser et al. 2000). A large number of GCM experiments have been dedicated to the quantification and understanding of the influence of regional or global SST anomalies on the climate and the atmospheric circulation [see the reviews of Frankignoul (1985) and Kushnir et al. (2002)]. Different ensembles of atmospheric GCM simulations forced by the last 50 yr of SST and sea ice observed conditions have been able to reproduce part of the observed circulation decadal changes in the Northern Hemisphere (Rodwell et al. 1999; Mehta et al. 2000; Latif et al. 2000; Hoerling et al. 2001). In the experiment of Rodwell et al. (1999), the simulated atmospheric changes are related to the North Atlantic Ocean, while Latif et al. (2000) and Hoerling et al. (2001) have found that the oceanic forcing of the long-term NAO changes seems to be located in the tropical Pacific and Indian Oceans. Recently Hurrel et al. 
(2004) argue that the observed NAO trend during the last $50 \mathrm{yr}$ is partly controlled by tropical SST forcing. But Schneider et al. (2003) in another ensemble of simulations find no evidence of such a tropical forcing but shows that the observed trend mainly reflects internal atmospheric variability. The origin of the long-term variations of the Northern Hemisphere extratropical circulation and of the NAO still remains unclear, but the influence of the extratropical oceans on the atmosphere has been previously suggested.

To study the potential impact of the extratropical SST anomalies on the low-frequency atmospheric change, an idealized experiment with typical fixed SST anomaly forcing has also been widely used in order to understand the atmospheric sensitivity to extratropical oceanic boundary forcing (see the reviews of Frankignoul (1985) and Kushnir et al. (2002)]. While some of the simulations show a linear baroclinic response (Kushnir and Held 1996), most of the simulated responses were nonlinear and equivalent barotropic (Palmer and Sun 1985; Peng et al. 1995, 2003). The inconsistencies between the different simulated atmospheric responses have been interpreted by Peng et al. $(1995,1997)$ as a fundamental dependence of the atmospheric sensitivity to the background flow, and thus, to the model and the considered season. Furthermore, the atmospheric response is closely related to the internal atmospheric variability and the storm tracks (Peng and Robinson 2001), which can also explain the model and seasonal dependence. Peng et al. (2003) have suggested an extended eddy-feedback mechanim to explain the full atmospheric response. The symmetric part of the response may be "sustained by an anomalous eddy-vorticity forcing resulting from the SST induced perturbations in the Atlantic storm tracks." On the other hand, the sign asymmetry seems to result from the nonlinear self-interaction of heating forced anomalous flow.

Lunkeit and von Detten (1997) have systematically investigated the linearity of the atmospheric response to a North Atlantic SST forcing using a larger number of simplified GCM simulations. Their experiment demonstrates that the response is linear with respect to the amplitude, for a certain range of forcing, but is not linear with respect to the sign of the forcing. Kucharski and Molteni (2003) using a new simplified GCM also found that the simulated atmospheric response to a SST tripole forcing in the North Atlantic is not symmetric with respect to the sign of the forcing. They have suggested that the asymmetry of the response is mainly caused by the asymmetry of the heating anomaly in the subtropical region, but also by the difference in the transient vorticity forcing. Sutton et al. (2001) have studied the atmospheric response to the different parts (sub- tropical and extratropical) of the SST tripole in the North Atlantic. They have shown that the extratropical atmospheric response is maintained by both the subtropical and extratropical parts of the SST tripole. They have also found evidence of nonlinear interactions between the atmospheric response to the subtropical SST forcing and the response to the extratropical SST forcing.

In a previous study, we have assessed the transient atmospheric response to North Atlantic SST tripolar anomalies ( $\mathrm{Li}$ and Conil 2003b). These transient experiments were designed to underline the fundamental processes that maintain the equilibrium and stationary response but also to provide evidence that multiple time scales exist for the development of the response. We showed that a linear baroclinic response grows rapidly (1-2 days), propagating from the surface to the upper levels. After 2 to 3 days, a nonlinear equivalent barotropic response is first achieved in the upper levels and then propagates downward. Afterward, the total atmospheric response is dominated by the nonlinear equivalent barotropic component. This study thus provides an evolutionary picture of the atmospheric response and of its barotropic and baroclinic components.

While influences of SST anomalies have received much attention during the last $20 \mathrm{yr}$, few studies have been dedicated to the assessment of the influence of the modified sea ice on the atmospheric circulation, and most of these works have been highly idealized. Menendez et al. (1999) have studied the impacts of a global sea ice removal in the Southern Hemisphere. Simmonds and Budd (1991) and Murray and Simmonds (1995) have, respectively, investigated the effect of uniform changes in the sea ice concentration (not in the sea ice edge) in the Southern and the Northern Hemisphere. These works have shown that, over a sea ice reduction, the increase of the sensible (and latent) heat flux maintain a substantial atmospheric warming. The decrease of the sea ice also produces a weakening of the midlatitude westerlies and a fall of the high-latitudes sea level pressure. Although these previous experiments have shown that the largest impact of the sea ice perturbations is found during the winter season, Hudson and Hewitson (2001) have examined the effect of realistic sea ice modifications around the Antarctic in summer.

Recently, two companion papers by Magnusdottir et al. (2004) and Deser et al. (2004) have investigated the atmospheric response simulated by the third National Center for Atmospheric Research (NCAR) Community Climate Model (CCM3) to modifications of the SST and sea ice in the North Atlantic. They have shown that the atmospheric response to a dipolar sea ice extent (SIE) anomalies is strong and similar to a negative phase of the simulated NAO. In their simulations, the 
atmospheric response to the SIE forcing is larger than the response to SST forcing. Their experiments indicate that the atmospheric response is highly asymmetric about the sign of the forcing and is linear with respect to the amplitude of the forcing. Using the same GCM (CCM3) as in the two previous studies, Alexander et al. (2004) assessed the influence of extreme Arctic SIC and SIE on the atmosphere. They have shown that the SIC forcing has a larger (smaller) impact on the large-scale indirect (local direct) response than the SIE forcing.

In this work, we examine the atmospheric response to prescribed SST and SIC anomalies in the North Atlantic. We use a large ensemble of atmospheric GCM simulations forced with tripolar SST and dipolar SIC anomalies. We particularly assess the linearity of the simulated response and we focus on the winter season. The seasonal dependence of the atmospheric response will be described in a future paper. The main objectives of this work are the following: 1) to evaluate the dynamical and thermodynamical response to the individual SST and SIC forcings; 2) to examine how symmetric is the response; and 3) to investigate the linearity of the atmospheric responses to the combined SST and SIC forcings.

In the climate system, the SST and SIC anomalies are both present at the same time (mainly under the influence of the same atmospheric forcing). Understanding the influence of the two individual oceanic surface anomalies and also their combined effects on the atmosphere is key for developing a picture of the extratropical coupled climate system and to assess its predictability. Our numerical experiments provide a small but nonnegligeable contribution toward these objectives. Atmospheric GCMs are well-designed tools to study such problems even if it is now clear that the GCM studies of the atmospheric sensitivity to the extratropical oceanic boundary conditions are strongly model dependent.

The paper is organized as follows: the atmospheric GCM and the experimental design are described in the next section. In section 3 , we analyze the atmospheric response to the individual forcings. The effects of the combined oceanic forcings are presented in section 4 . Section 5 is dedicated to the assessment of the symmetry of the response. The conclusions are then summarized in the last section.

\section{Model and experiments}

The model used in this study is the GCM of the Laboratoire de Météorologie Dynamique (LMDZ, version 3.3), a state-of-the-art climate model modified from the original version (Sadourny and Laval 1984). The model is formulated through finite differencing on the Arakawa-C grid, with a horizontal resolution of $4^{\circ}$ in latitude and $5^{\circ}$ in longitude on a regularly distributed grid. The model uses vertical hybrid coordinates at 19 levels, unevenly spaced for a better resolution in the boundary layer. The advection scheme is designed to conserve potential enstrophy for divergent barotropic flow (Sadourny 1975). Lateral diffusion is calculated through an iterated Laplacian operator. The time step is set to $6 \mathrm{~min}$ in order to resolve the dynamics; however, the physical parameterizations are evaluated only at 30-min intervals. Convection is parameterized with a simple mass flux scheme developed by Tiedtke (1989). The cloud parameterization, presented in Le Treut and Li (1991), uses a cloud water budget and a statistical description of the subgrid water distribution. The radiation package is the same as used in the European Centre for Medium-Range Weather Forecasts (ECMWF) model. The shortwave radiation code is an updated version of Fouquart and Bonnel (1980) scheme. The longwave radiation scheme is from Morcrette (1991). The planetary boundary layer scheme is based on a secondorder closure model. The surface model is a "bucket" model where we consider a homogeneous layer of 150 $\mathrm{mm}$. Calculation of the surface temperature is incorporated in the boundary layer and based on the surface energy balance equation. For the surface moisture, a holding capacity is fixed to $150 \mathrm{~mm}$ of water, where all water above this value is lost as runoff. (A complete description of the model is available online at http://www. lmd.jussieu.fr $/ \sim \operatorname{lmdz} /$ doc.html.) The same version of the GCM was also used in the coupled ocean-atmosphere study presented in $\mathrm{Li}$ and Conil (2003a) and in the interannual predictability study of Conil and $\mathrm{Li}$ (2003).

The dominant modes of the North Atlantic SST and SIC variability are primarily forced by the NAO (Czaja and Frankignoul 2002; Deser et al. 2000). Our main objective is to study the atmospheric sensitivity to these SST and SIC anomalies in order to quantify their potential feedbacks on the atmosphere. The SST and SIC data were derived from version 1.1 of the Hadley Centre Sea Ice and SST (HadISST1.1) dataset over the period 1950-94. We characterize typical patterns of SST and SIC associated with the NAO by compositing the strong positive $(1973,1974,1975,1976,1981,1983$, $1984,1989,1990,1991,1992,1993,1994)$ minus negative (1955, 1956, 1960, 1962, 1963, 1964, 1965, 1966, 1969 , $1970,1977,1978,1979)$ NAO years, defined as above and below a one standard deviation threshold. We use a consensus between the NAO station based index defined by Hurrel (1996) and the first PC of the SLP anomalies over the North Atlantic region to define the strong NAO years (see online at http://www.cgd.ucar.edu/ cas/jhurrell/naointro.html). The typical SST and SIC anomalies are defined to follow a realistic seasonal 

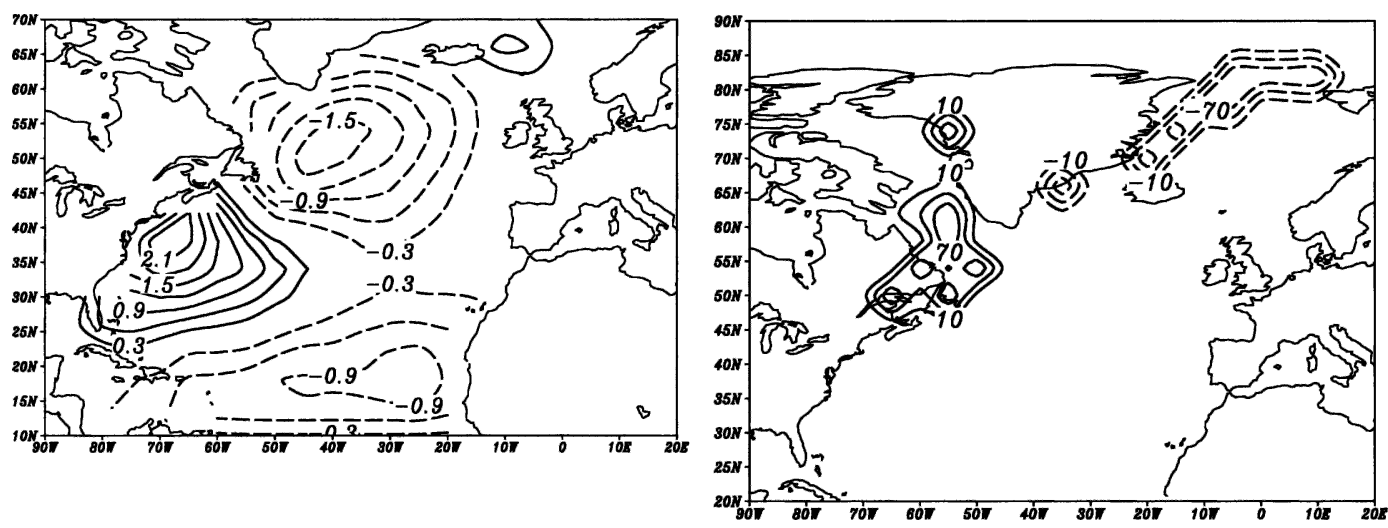

FIG. 1. (left) SST and (right) SIC anomalies during winter [Dec-Feb (DJF)] used in the TRI, DIP, and TRIDIP experiments. Contour intervals are $0.3 \mathrm{~K}$ in the left panel. The $10 \%, 40 \%$, and $70 \%$ levels are contoured in the right panel.

cycle. Figure 1 shows the spatial structure of the winter oceanic perturbations used in the experiments.

These patterns are not sensitive to the chosen period or to the definition of a strong NAO event. They also correspond to the first dominant mode of variability of SST (Deser and Blackmon 1993) and SIC (Deser et al. 2000) in the North Atlantic and Arctic. The SST anomalies are similar to those used by Peng et al. (2002) and Rodwell et al. (1999); they are scaled to have a maximum of $2^{\circ} \mathrm{C}$ in order to obtain a more robust response but the SIC anomalies are realistic. The SST and SIC anomalies present two distinct maxima, one during winter around January and one during spring around April.

The experiment nicknamed "CLIM," which serves as the "control" experiment, is a 150 -yr simulation where the oceanic boundary conditions (SST and SIC) are climatological. The climatological SST and SIC are computed as the mean seasonal cycle over the period 1950-94. Using the previously described oceanic boundary anomalies, we conducted six different experiments. In the TRIp and TRIm experiments the SST tripolar anomalies are, respectively, added and substracted to the surface climatology. The experiments DIPp and DIPm, respectively, use the positive and negative SIC dipole pattern to force the atmospheric GCM. In the last two experiments, TRIDIPp and TRIDIPm, we combine the SST and SIC, positive and negative, typical anomalies, respectively. The oceanic forcings are only included in the North Atlantic, north of $10^{\circ} \mathrm{N}$, and a buffer zone is prescribed between $0^{\circ}$ and $10^{\circ} \mathrm{N}$ in order to smooth the transition between the climatology and the forcing. The length of the six simulations is $50 \mathrm{yr}$ in order to increase the statistical significance of the response. Table 1 summarizes the main oceanic boundary characteristics used in the different experiments.

In this work, the symmetric part of the atmospheric response is defined as the difference between the longterm means of the "positive" and "negative" experiments. This is the part of the response that is symmetric with respect to the sign of the forcing. The asymmetry of the atmospheric response can be seen in the difference between the long-term means of the perturbed and control experiments, as shown in section 5.

An important part of the study concerned the linearity of the response to the combined SST and SIC forcings. We measure the degree of nonlinearity by taking the difference between the response to the combined forcing and the responses to the individual SST and SIC forcings, for example, [TRIDIPp - TRIDIPm] [(TRIp - TRIm) + (DIPp - DIPm)].

\section{Winter mean response to the individual SST and SIC forcing}

In this section, we will assess the symmetric $(\mathrm{P}-\mathrm{M})$ atmospheric responses induced by the SST and SIC

TABLE 1. The SST and SIC distributions used as oceanic boundary conditions in the different numerical experiments and their length.

\begin{tabular}{lllc}
\hline \hline \multicolumn{1}{c}{ Expt } & \multicolumn{1}{c}{ SST } & SIC & Length \\
\hline CLIM & Climatological & Climatological & $150 \mathrm{yr}$ \\
TRIp & Clim + tripolar anomalies & Climatological & $50 \mathrm{yr}$ \\
TRIm & Clim - tripolar anomalies & Climatological & $50 \mathrm{yr}$ \\
DIPp & Climatological & Clim + dipolar anomalies & $50 \mathrm{yr}$ \\
DIPm & Climatological & Clim - dipolar anomalies & $50 \mathrm{yr}$ \\
TRIDIPp & Clim + tripolar anomalies & Clim + dipolar anomalies & $50 \mathrm{yr}$ \\
TRIDIPm & Clim - tripolar anomalies & Clim - dipolar anomalies & $50 \mathrm{yr}$ \\
\hline
\end{tabular}



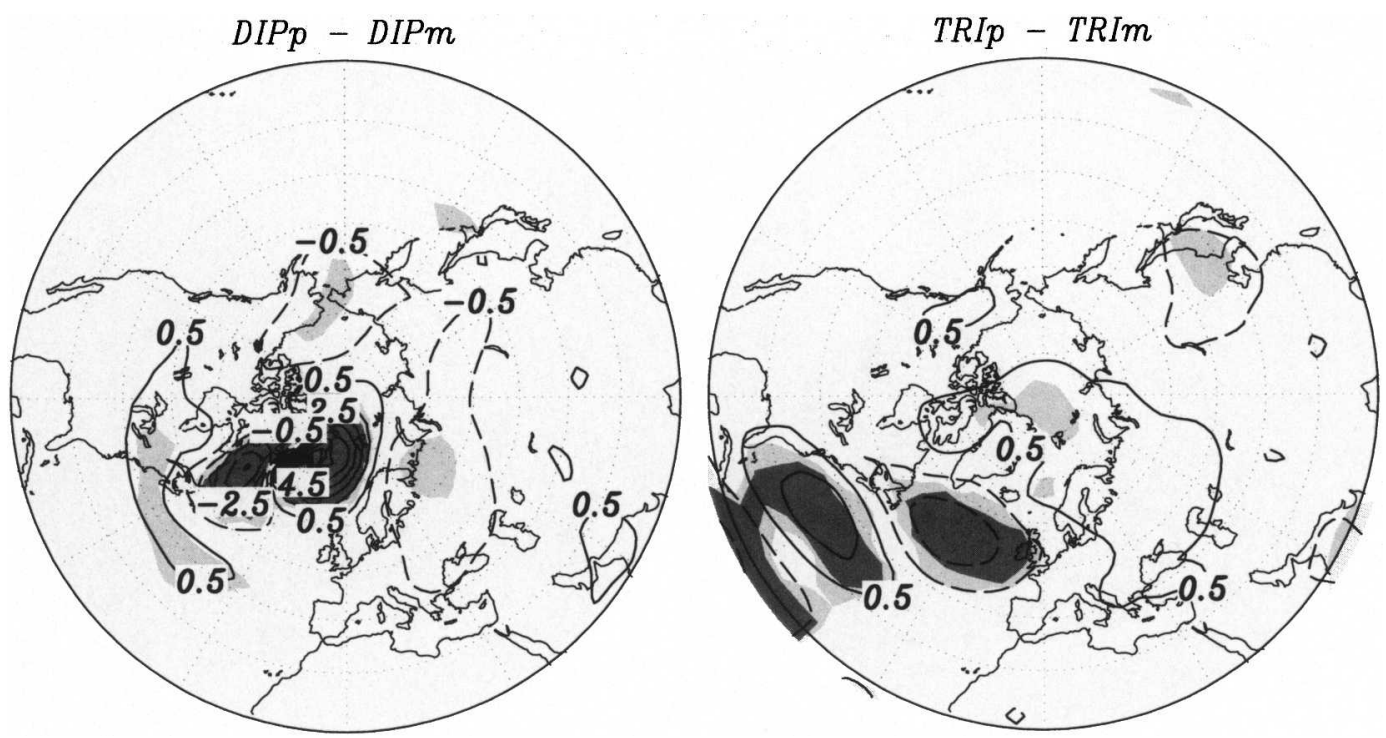

FIG. 2. Temperature at the 850-hPa symmetric response to the (left) SIC and (right) SST forcing in winter (DJF). Contour intervals are $0.5^{\circ} \mathrm{C}$ and one of every two contours is labeled. The light (dark) gray shaded regions show the $90 \%(99 \%)$ significance level of the response according to a standard $t$ test.

forcings separately. The total response, defined as the response to the combined SST and SIC forcings, will be examined in the next section.

The variations of the SIC have a huge effect on the surface temperature (not shown). The symmetric response of the surface temperature to the SIC dipole stands between $-14^{\circ}$ and $24^{\circ} \mathrm{C}$, much larger than the symmetric response to the SST tripole, ranging between $-2^{\circ}$ and $2^{\circ} \mathrm{C}$. We also notice that the impact on the surface temperature of the SIC decrease is stronger than the impact of the SIC increase.

Figure 2 shows the $850-\mathrm{hPa}$ temperature (T850) response to the SST tripole and SIC dipole. The effect of the SIC dipole is still very large, but it is weaker at $850 \mathrm{hPa}$ than at the surface whereas the temperature responses to the SST tripole are similar at the surface and at $850 \mathrm{hPa}$. In the TRI and DIP experiments, the low-level temperature response is mainly located in the vicinity of the forcing. The remote temperature response to the SST tripole or SIC dipole forcing is much weaker and generally not significant. The impact of the SIC anomalies on the low-level temperature is much larger than that of the SST. Above the SIC (SST) forcing the T850 anomaly reaches a maximum of $7^{\circ} \mathrm{C}\left(2^{\circ} \mathrm{C}\right)$. These two dominant contributions maintained by the SST tripole and the SIC dipole both affect the symmetric total response in the TRIDIP experiment presented in the next section.

The vertical structure of the temperature response in the two experiments, over the North Atlantic-Europe region is shown in Fig. 3. The vertical profiles of the air temperature response to SST and SIC forcings are different. The effects of the SIC dipole are very strong near the surface in the high latitudes. The vertical decrease is important and the temperature response changes sign in the midtroposphere. The tripolar SST anomalies create a temperature response extending from the surface to the upper troposphere, the larger effect residing in the boundary layer. The temperature response has a similar amplitude in the Tropics and in the extratropics. In the lower (upper) troposphere, the SST impact on temperature structure is smaller (larger) than the SIC impact. The remote response to the SST tripole is also important in the high latitudes.

The simulated symmetric 500-hPa geopotential height $\left(Z_{500}\right)$ response to the individual SST and SIC forcings are presented in Fig. 4. The SIC anomalies maintain a significant large-scale pattern of $Z_{500}$ anomalies reaching a maximum amplitude of $20-25 \mathrm{~m}$. The most significant part of the response is located over the forcing in the Greenland Sea region. This pattern is different from both observed NAO and simulated NAO, which is approximately defined as the model's leading variation mode (see the appendix). In some aspects, it is close to the residual or "direct" simulated $Z_{500}$ response to the SIC dipole presented by Deser et al. (2004). We can also notice a significant "indirect" response far away from the forcing.

The simulated $Z_{500}$ response to the SST tripole is dominated by a high-latitude structure. It is mainly formed by a cyclonic anomaly located in southeast Greenland reaching $35 \mathrm{~m}$ and an anticyclonic center over Siberia. Over the subtropical North Atlantic, the $Z_{500}$ anomaly is also significant but much weaker. Over the North Atlantic-Arctic region, this pattern projects strongly on the model's leading mode of variability (see 

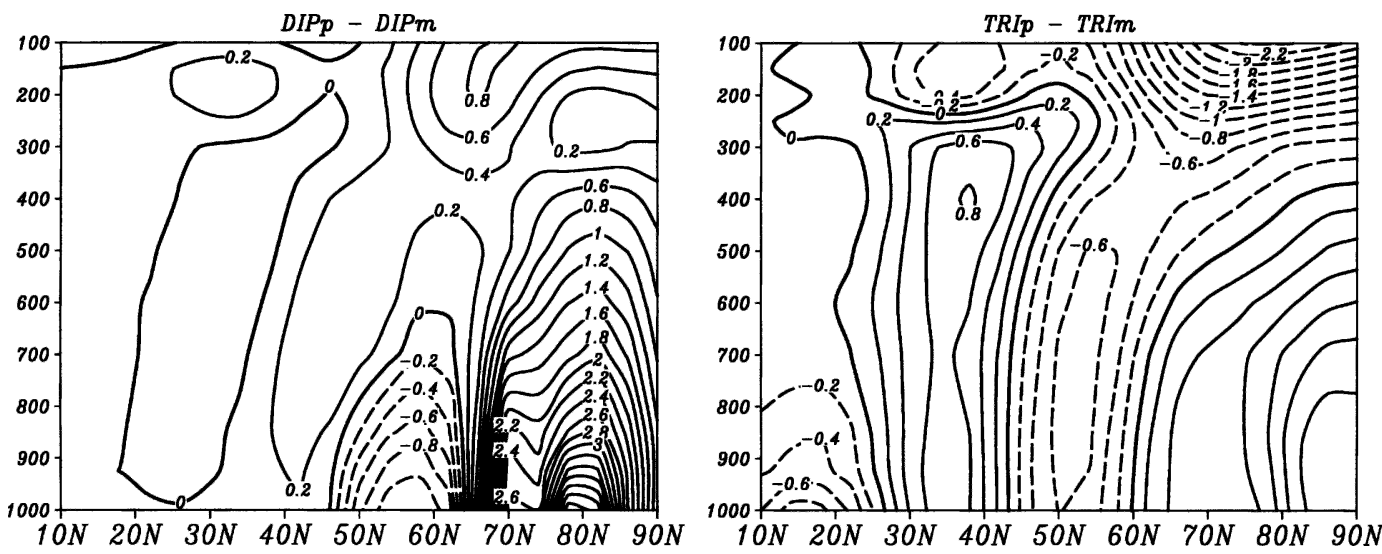

FIG. 3. Latitude-height cross section showing zonal mean $\left(90^{\circ} \mathrm{W}-30^{\circ} \mathrm{E}\right)$ winter temperature symmetric response in the (left) DIP and (right) TRI experiments (units: ${ }^{\circ} \mathrm{C}$ ).

the appendix) considered as the simulated NAO pattern. The SST tripolar anomalies maintain an increase of the pressure over the North Atlantic between $25^{\circ}$ and $40^{\circ} \mathrm{N}$ and a decrease of the pressure in the high latitudes south of the Iceland. This suggests a weak positive feedback between the NAO and the SST tripole in the North Atlantic region.

Let us now make a short comparison between our results and those of other groups. The studies of Cassou (2001) and Sutton et al. (2001) were devoted to the quantification of the atmospheric response to the lowlatitude and extratropical parts of the SST tripole. The main objectives of these studies are to understand which part of the SST tripole controls the total response and to determine the linearity of the responses to the addition of midlatitude and subtropical forcings. They show that the third version of the Hadley Centre Atmospheric Model (HadAM3) and the Arpege GCM's responses to the SST tripole are dominated by a wavelike pattern emanating from the tropical Atlantic. The simulated response to the extratropical part of the tripole is very weak compared to the low-latitude SST effects. They also present evidence of nonlinear interactions between the responses to the extratropical and low-latitude parts of the SST tripole and mean circulation. In our experiments, as well as in Rodwell et al. (1999) and Peng et al. (2002), the forcing is stronger (weaker) in the extratropics (low latitudes). The $Z_{500}$ response seems to be more constrained by the extratropical part of the tripole, and is not similar to the wave train pattern emerging in the HadAM3 and Arpege GCMs. Analysis of the $200-\mathrm{hPa}$ streamfunction re-
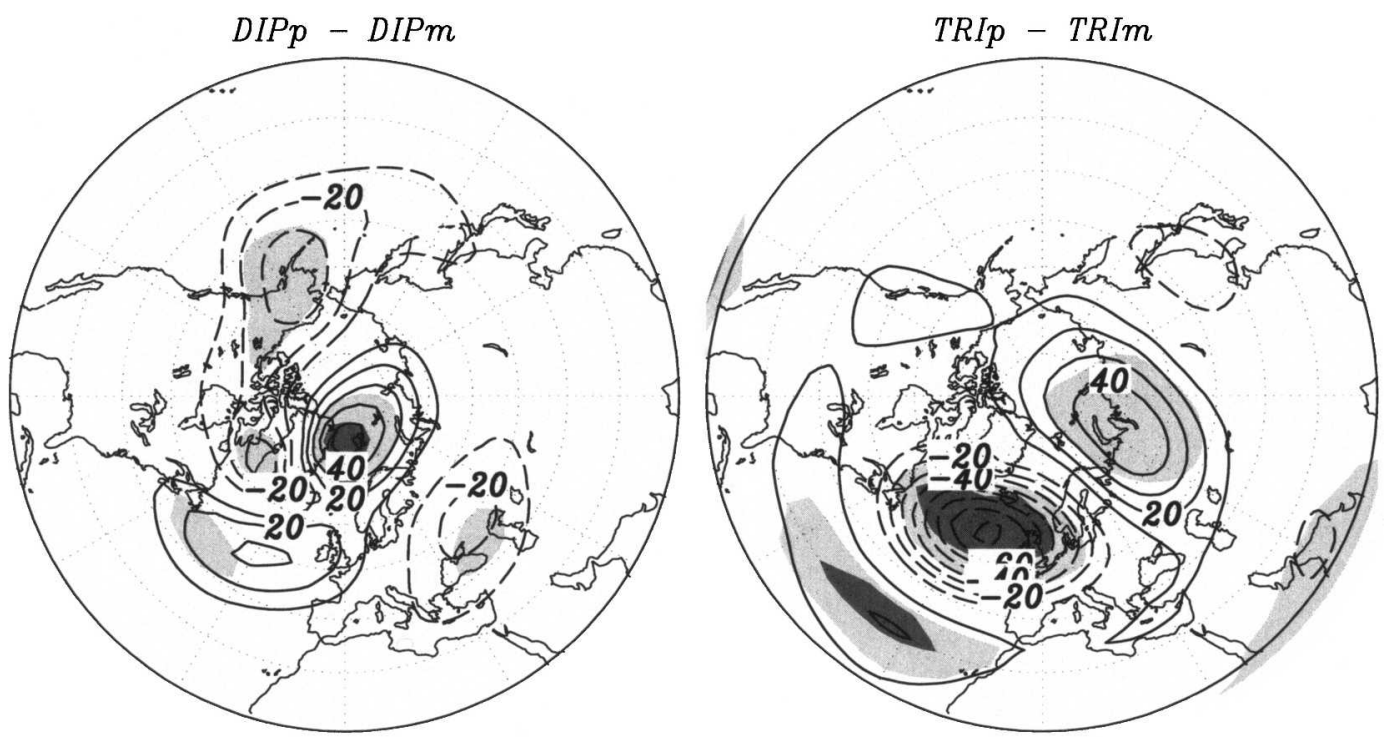

FIG. 4. Geopotential height at the 500-hPa symmetric responses in the (left) DIP and (right) TRI experiments in winter (DJF). Contour intervals are $10 \mathrm{~m}$. The light (dark) gray shaded regions show the $90 \%(99 \%)$ significance level of the response according to a standard $t$ test. 

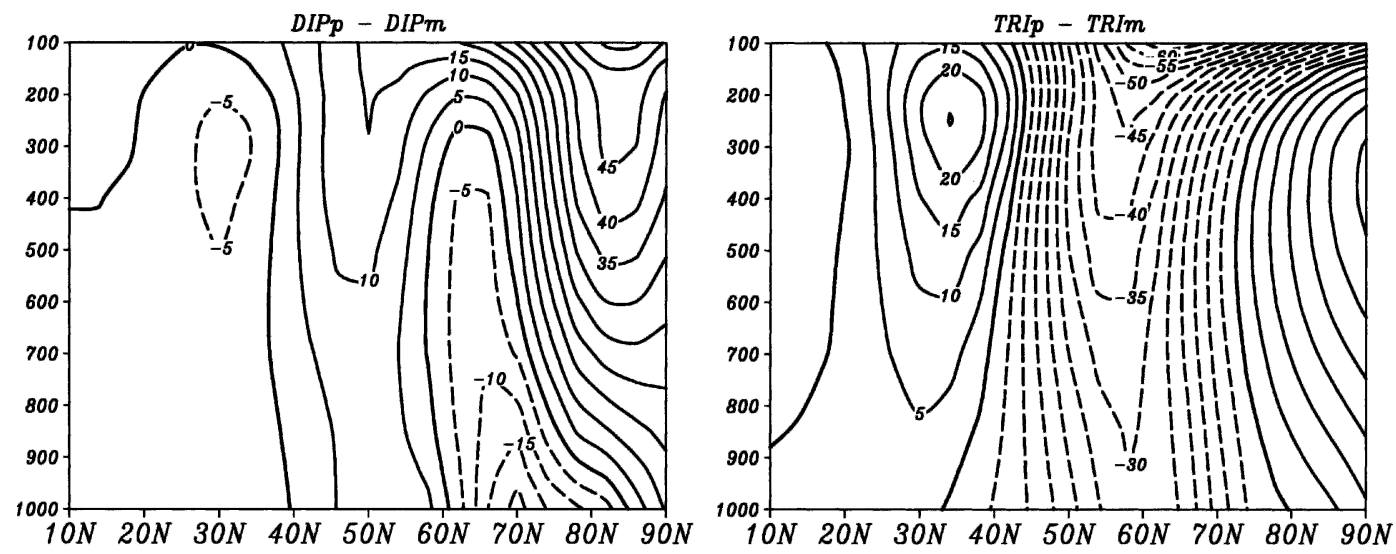

FIG. 5. Latitude-height cross section showing zonal mean $\left(90^{\circ} \mathrm{W}-30^{\circ} \mathrm{E}\right)$ winter geopotential height symmetric response in the (left) DIP and (right) TRI experiments (units: m).

sponse also revealed that the tropical part of the response is weaker in our simulation compared to Cassou (2001) and Sutton et al. (2001). Previous analysis (Li and Conil 2003b) of the transient response to the SST tripole also suggested that our model is particularly sensitive to the extratropical part of the SST tripole. Finally, we should point out that the combination of subtropical and midlatitude responses is highly nonlinear, as reported in Kucharski and Molteni (2003). They found that a significant subtropical response extending to the midlatitudes was induced by the heating anomaly and was nonlinearly related to the response from transient eddies, which was prominent in the maintenance of the largescale atmospheric response for regions north of $40^{\circ} \mathrm{N}$.

The vertical structure of the geopotential winter mean response in the North Atlantic-Europe region is presented in Fig. 5.

The geopotential height response to the SIC dipole forcing is important above the largest thermal forcing between $45^{\circ}$ and $90^{\circ} \mathrm{N}$. The maximum negative anomaly is located in the midtroposphere $\sim 70^{\circ} \mathrm{N}$. Between $20^{\circ}$ and $50^{\circ} \mathrm{N}$, the response is weaker and its maximum is located in the upper troposphere.

The SST tripole forcing leads to large geopotential anomalies from the subtropics to the North Pole. The geopotential response is equivalent barotropic, increasing from the low levels to the upper levels with a maximum at the tropopause. A large negative anomaly reaching more than $45 \mathrm{~m}$ is centered at $55^{\circ} \mathrm{N}$ and is surrounded by two slightly weaker positive anomalies in the subtropics and at high latitudes.

The SST and SIC forcings maintain geopotential anomalies with completely different spatial distributions. During winter, the geopotential response to the SST tripole is larger. While the main negative response is centered at $55^{\circ} \mathrm{N}$ in the TRI experiment, it is much farther north in the DIP experiment $\left(70^{\circ} \mathrm{N}\right)$.
Over a cooling of the ocean or an increase of the sea ice, the atmospheric temperature in the boundary layer and above decreases. The local reduction of the temperature induces a direct thermal response and the formation of an upper-level cyclonic anomaly/lower-level anticyclonic anomaly. This direct thermal response is then able to modify both the mean atmospheric flow and the transient characteristics. Such modifications can lead to a large indirect response, depending on the location of the forcing, and on the main dynamical characteristics.

The net heat flux response to the two individual oceanic forcings is shown in Fig. 6. The response is dominated by the local effects of the oceanic anomalies. Over a cooling (warming) anomaly, the surface heat flux anomaly tends to cool (warm) the air and would, in a coupled system, warm (cool) the ocean. The behavior of the surface heat flux has been largely explained by Barsugli and Battisti (1998) using a simple model for coupled and uncoupled systems. The impact of the SST anomalies is mostly between $20^{\circ}$ and $60^{\circ} \mathrm{N}$. In this region the net surface heat flux response to the SST forcing is dominated by the latent heat contribution over the sensible heat flux by a factor of 2 .

The surface heat flux is extremely sensitive to changes in SIC (left panel in Fig. 6). The modification in SIC leads to a dipolar heat flux and precipitation response around the forcing, similar to that obtained by Magnusdottir et al. (2004). Over a retreat of the sea ice, there is a large negative heat flux anomaly, because of the new possible interaction between open waters and the atmosphere. As the sea ice disappears, the ocean is able to warm the lower atmosphere. In this case, the total surface heat flux anomaly is dominated by the sensible component. Downstream from the sea ice retreat, there is a small opposite (positive) anomaly due to the local low-level atmospheric warming. In the region surrounded by sea ice, the advected air is very cold 

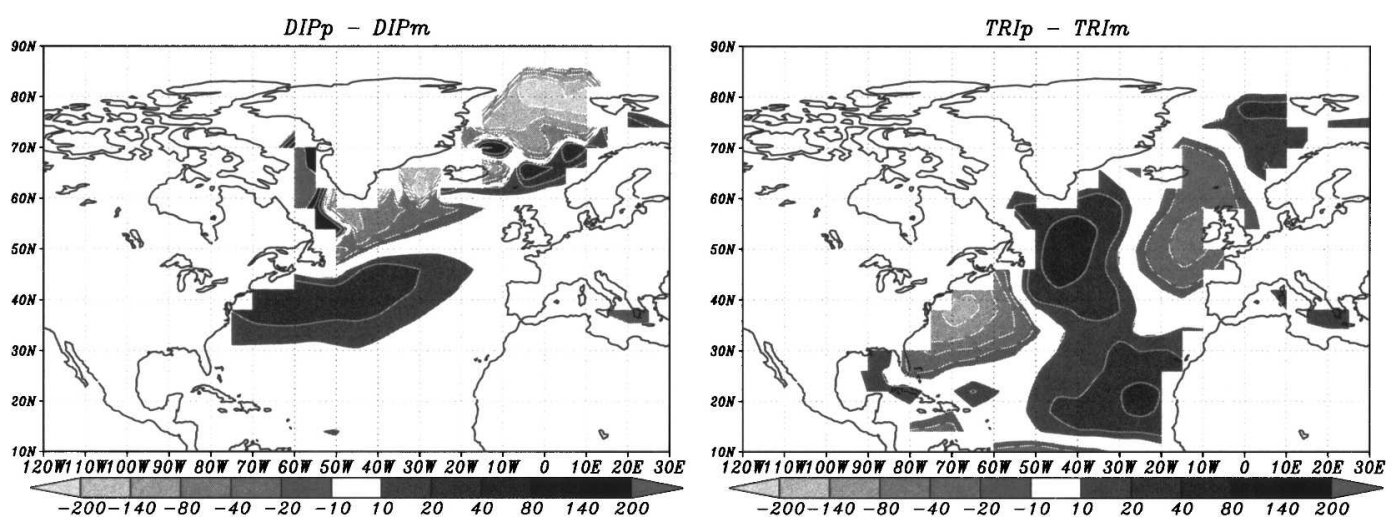

FIG. 6. Net surface heat flux symmetric responses in the (left) DIP and (right) TRI experiments in winter (DJF; units: $\mathrm{W} \mathrm{m}^{-2}$ ). The contours shown are $-200,-140,-80,-40,-20,-10,10,20,40,80,140$, and $200 \mathrm{~W} \mathrm{~m}^{-2}$. Positive heat flux anomalies correspond to a cooling tendancy of the air above the surface.

and the warming from the ocean is important. When the sea ice disappears, the advected air is warmer and the ocean-atmosphere temperature gradient is weaker, thus, the warming from the ocean decreases.

When the sea ice coverage is extended, the atmosphere can no longer interact with the ocean, and a local anomalous heat flux toward the ocean appears. The extension of the sea ice is also accompanied by a cooling and drying of the near-surface air. When the colder near-surface air is advected, it is warmed by the ocean, creating an anomalous heat flux toward the atmosphere. The heat flux response around the SIC forcing is largely dominated by this dipolar effect. But the large-scale atmospheric change due to the SIC anomalies also creates a large anomalous heat flux in the midlatitudes of the North Atlantic, which supports a warming of the ocean around $40^{\circ} \mathrm{N}$ in the western North Atlantic. The effect of the SST tripole is much smaller. It is also mainly localized over the SST anomalies, except around the British Isles where a negative heat flux response is found, corresponding to a warming of the low-level air.

The changes in the atmospheric circulation and in the surface heat/water flux are associated with modifications of the transient properties of the atmosphere. The large-scale modification of the atmospheric circulation induced by the oceanic forcings is associated with changes in the main characteristics of the storm tracks (Fig. 7). The storm tracks are estimated using the standard deviations of the 2.5-6.5-day bandpass-filtered daily $Z_{500}$. Figure 7 shows the storm track perturbations generated by the SST tripole and the SIC dipole as well as the simulated climatological mean storm tracks.

The strong warming and the evaporation increase southeast of Greenland as well as the mean wind changes that are related to a northward shift of the storm tracks in the DIP experiments. In contrast, the
SST tripole maintains an opposite southward shift of the storm tracks. This result is consistent with the storm track perturbations noticed by Magnusdottir et al. (2004) using a different GCM.

\section{Winter mean response to combined SST and SIC forcing: The TRIDIP experiments}

In this section we will examine the atmospheric response to the combined SST and SIC forcings. Again, we study only the symmetric response induced by the difference between positive and negative phases of the oceanic forcing. Our experimental design allows us to assess the linearity of the combination of the two oceanic forcings. We will thus explore the difference between the combined experiment (TRIDIP) and the linear addition of the DIP and TRI experiments.

The direct effect of the surface changes on the air temperature extends through the lower troposphere. The upper-left panel in Fig. 8 shows the 850-hPa temperature $\left(T_{850}\right)$ symmetric response to the combined SST and SIC forcings. The spatial patterns of the $T_{850}$ and the surface air temperature responses have many common characteristics. In the forcing regions, the magnitude of the temperature anomalies are smaller at $850 \mathrm{hPa}$ compared with the surface. Furthermore, a significant remote impact above the east Asian continent appears at $850 \mathrm{hPa}$. The total symmetric $850-\mathrm{hPa}$ temperature response mostly reflects the two effects of the sea ice and the SST changes. The largest response is obtained at high latitudes around Greenland and is due to the SIC dipole. The upper-right panel in Fig. 8 presents the difference between the TRIDIP symmetric response and the linear addition of the TRI and DIP responses. The nonlinear part of the $T_{850}$ is weak in the forcing regions but reaches important values in the remote areas such as North Africa, Siberia, and the Bering Strait region. The spatial correlations between the tem- 

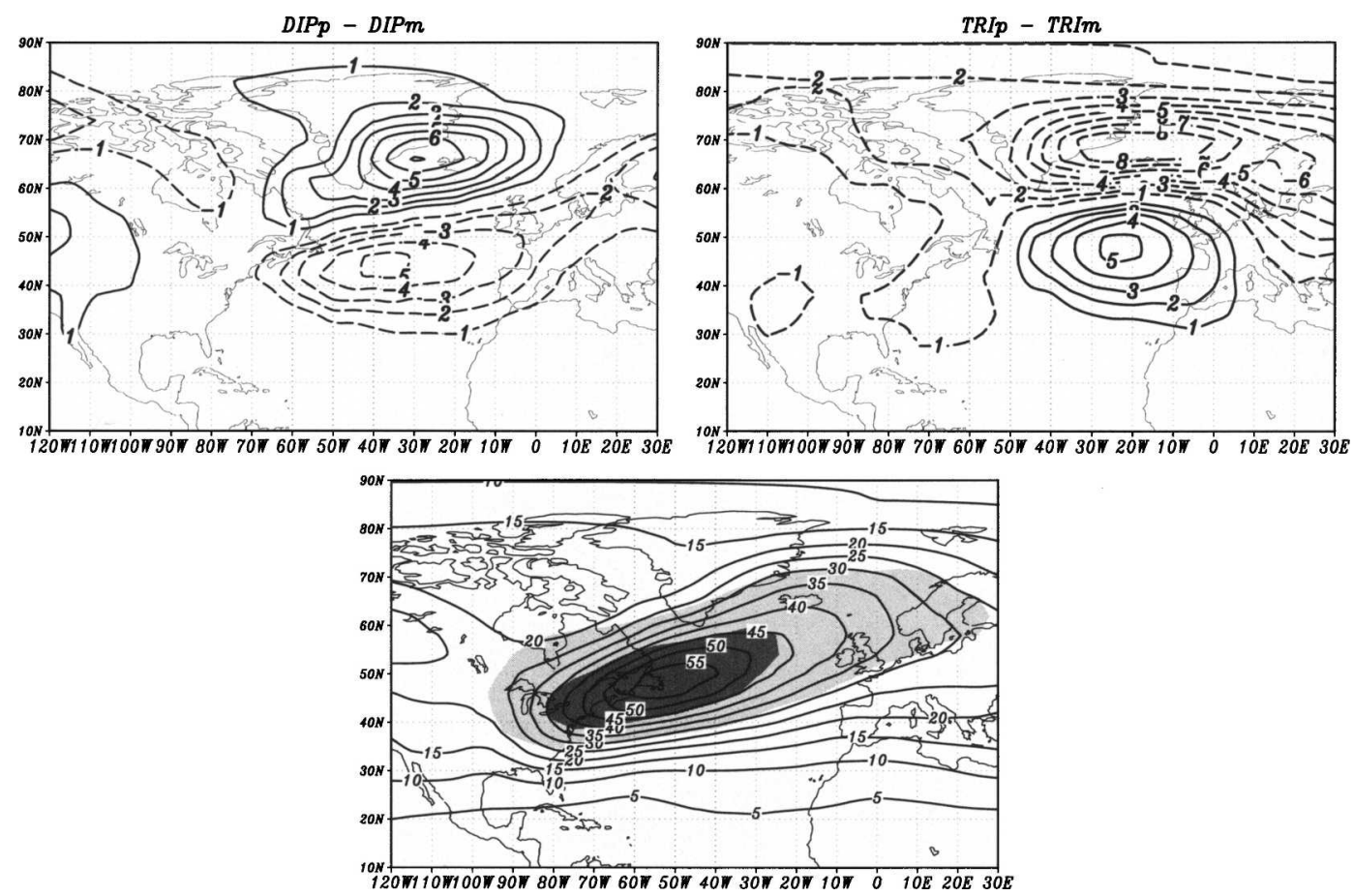

FIG. 7. Storm tracks (std dev of bandpass-filtered daily $Z_{500}$ ) symmetric response in the (upper left) DIP and (upper right) TRI experiments in winter (units: m). (lower) Mean storm tracks during winter in the CLIM 150-yr simulation (contour; contour intervals are $5 \mathrm{~m}$ ) and the NCEP reanalysis over the period 1966-94 (shadings; the light and dark gray shadings show the 30- and 40-m levels, respectively).

perature response to the combined forcing and the temperature responses to the SST tripole and SIC dipole at $850 \mathrm{hPa}(500 \mathrm{hPa})$ are 0.5 and 0.9 (0.6 and 0.52$)$, respectively.

The vertical distribution of the temperature response in the North Atlantic-Europe region $\left(90^{\circ} \mathrm{W}-30^{\circ} \mathrm{E}\right)$ is displayed in Fig. 9. In the Tropics, the temperature response is strongly baroclinic. The cooling of the tropical Atlantic maintains a negative air temperature anomaly in the lower troposphere (below the 750-hPa level). This lower-atmosphere cooling is balanced by a slight warming of the upper troposphere. In the midlatitudes, the SST tripole impacts the air temperature in the entire troposphere. While the air temperature response keeps the same sign, it weakens significantly from the surface to the tropopause. At high latitudes, the SIC modification effects are strong and mostly baroclinic. The air temperature response is large near the surface but its vertical extension is small, mostly limited in the lower troposphere, especially in the boundary layer.

The temperature response to the combined forcing is very large in the lower troposphere and in the high latitudes while decreasing from the high to the low latitudes and from the lower to the upper troposphere. The vertical structure of the temperature response contains an interesting feature near the tropopause. From the midlatitudes $\left(30^{\circ} \mathrm{N}\right)$ to the North Pole, the tropospheric temperature response is balanced by an opposite response in the lower stratosphere above the tropopause. The opposition of the lower-stratospheric response is mainly constrained by the radiative equilibrium of the entire atmospheric column.

The nonlinear interactions between the DIP responses and the TRI responses are weak throughout the entire troposphere (see right panel in Fig. 9.). They maintain a slight northward tilt reaching its largest effects in the midtroposphere. The combination of the individual responses is mainly linear on the temperature for the entire troposphere. But the nonlinearity issued by the combination of SST and SIC seems to induce a southward shift of the atmospheric response structure.

In association with perturbations of the thermal structure, the atmospheric circulation is also modified. The surface pressure (not shown) is increased locally over the SIC augmentation, consistent with the surface air cooling. Above the SIC reduction, or the midlatitude SST warming, the air temperature increases and the surface pressure decreases. Far from the local forcings, a large positive surface pressure anomaly is located over a broad area of the Arctic and Siberia. This surface pressure increase is not associated with any significant temperature change and may reflect the largescale changes prominent in the free troposphere. 


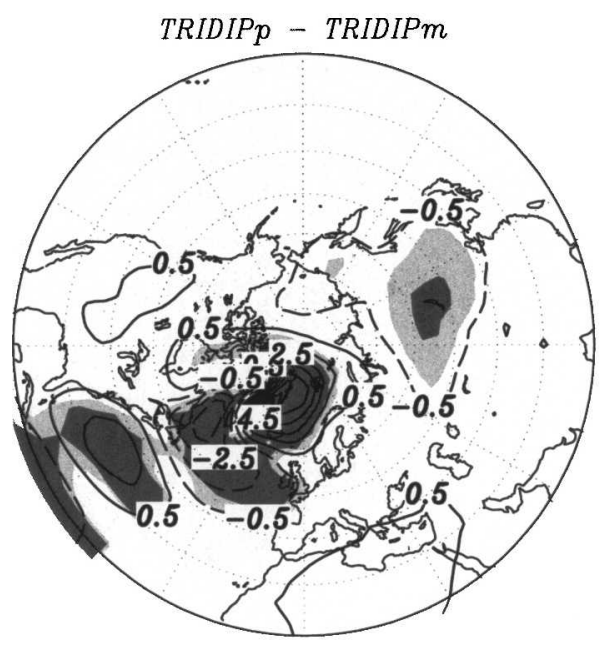

$($ TRIDIPp-TRIDIPm) $-[(T R I p-T R I m)+(D I P p-D I P m)]$

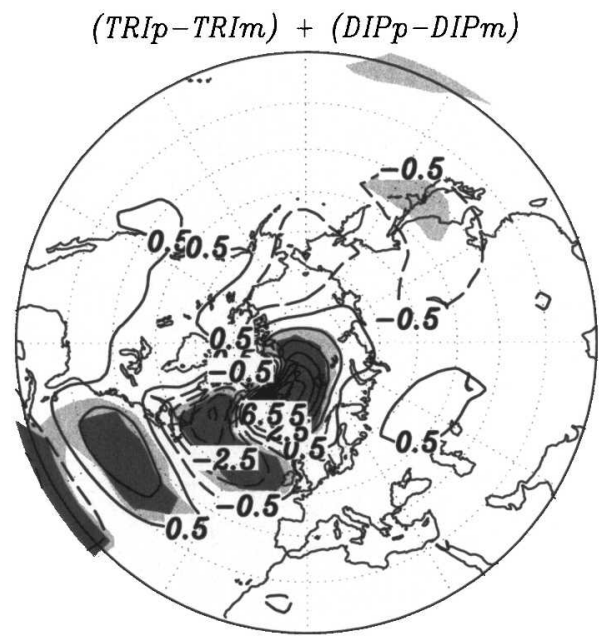

FIG. 8. Temperature at the 850-hPa symmetric total response in the (upper left) TRIDIP experiment and (upper right) the difference with the linear addition of the SST and SIC responses in winter (DJF). (lower) The linear addition of the SST and SIC responses (TRIp - TRIm) + (DIPp - DIPm). Contour intervals are (upper left and lower) $0.5^{\circ} \mathrm{C}$ and (right) $0.3^{\circ} \mathrm{C}$ and one of every two contours is labeled. In the upper-left and lower panels, the light (dark) gray-shaded regions show the $90 \%$ (99\%) significance level of the response according to a standard $t$ test.

The 500-hPa geopotential height total response (upper-left panel in Fig. 10) is dominated by large-scale changes that are much larger than the local thermal effects as also underlined in Alexander et al. (2004). In fact, in the free atmosphere above the boundary layer, the local responses are of secondary order. The geopotential response is mainly formed by a strong dipole with a pressure increase over the Arctic and Siberia, and a decrease lying between the Greenland and the British Isles. This dipolar structure is prominent in the free troposphere, from the top of the boundary layer to the tropopause. The dipole between the Arctic and the North Atlantic Ocean is well developed and is significant at the $95 \%$ level, according to a standard $t$ test. Apart from this large-scale prominent dipole, very few regions experience a significant $Z_{500}$ linear response. In contrast to the temperature responses, the contribution of the nonlinear interactions of the TRI and DIP responses is more important on the geopotential height. The largest nonlinear effects are found in the main centers of action in the North Atlantic-Greenland region. They mainly contribute to the southward displacement of the main centers already seen in the TRI responses. This shift due to the nonlinearity is coherent with the same behavior visible for temperature (Fig. 9). Finally, we should remark that the total 500-hPa geopotential height symmetric response projects significantly on the first mode of the simulated internal variability (see the appendix), as is the case in the TRI experiment (Fig. 4).

The left panel in Fig. 11 shows a latitude-height cross section of the geopotential height response in the North Atlantic-Europe region $\left(90^{\circ} \mathrm{W}-30^{\circ} \mathrm{E}\right)$.

The geopotential height response is equivalent barotropic in the mid- and high latitudes, between $30^{\circ} \mathrm{N}$ and 

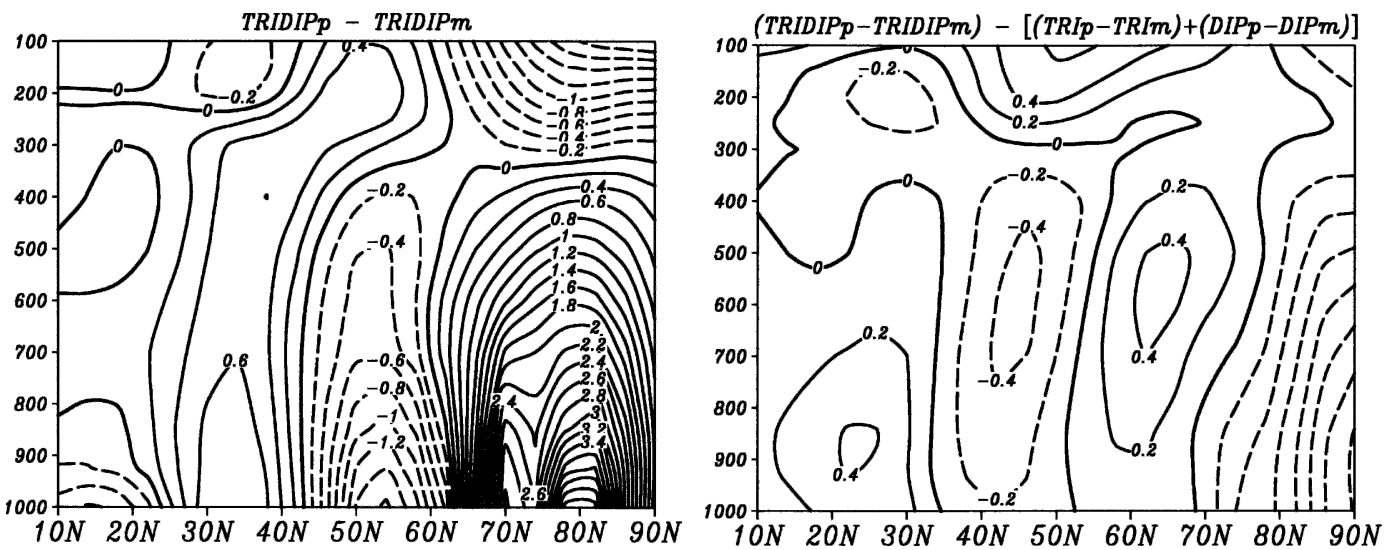

FIG. 9. Latitude-height cross section showing zonal mean $\left(90^{\circ} \mathrm{W}-30^{\circ} \mathrm{E}\right)$ winter (left) temperature response and (right) difference with the linear responses $(\mathrm{m})$.

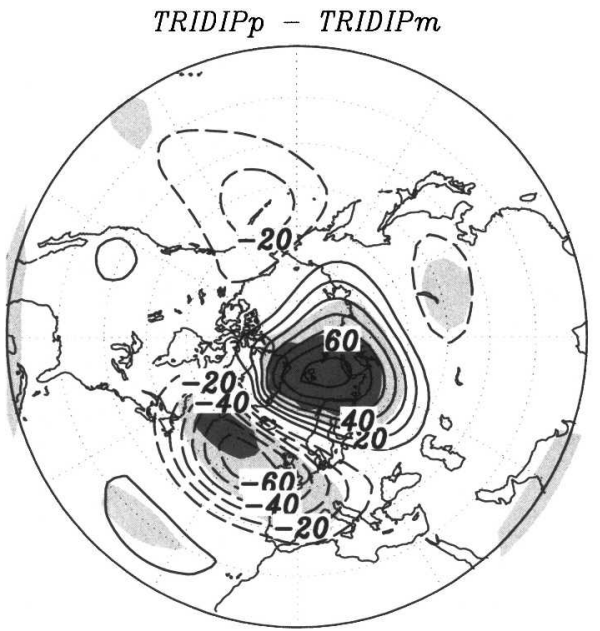

$(T R I D I P p-T R I D I P m)-[(T R I p-T R I m)+(D I P p-D I P m)]$

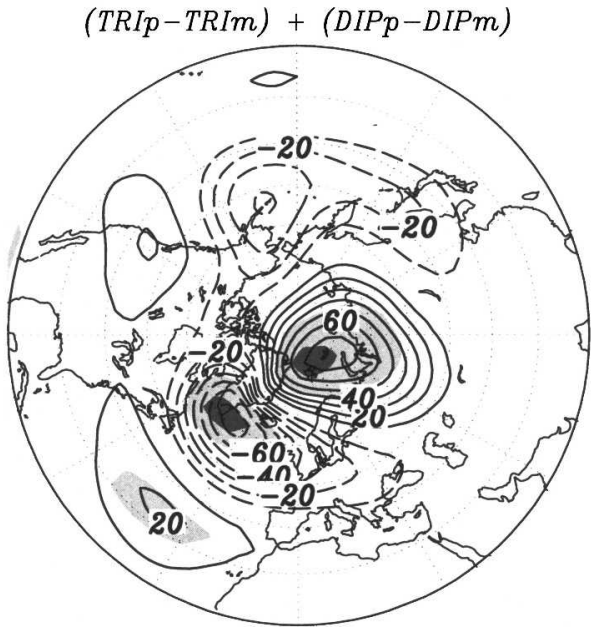

FIG. 10. The 500-hPa geopotential height symmetric total response in the (upper left) TRIDIP experiment and (upper right) difference with the linear addition of the SST and SIC responses in winter (DJF). The lower panel shows the linear addition of the SST and SIC responses (TRIp - TRIm) + (DIPp - DIPm). Contour intervals are $10 \mathrm{~m}$ and one of every two contours is labeled. In the upper-left and lower panels, the light (dark) gray shaded regions show the $90 \%$ (99\%) significance level of the response according to a standard $t$ test. 

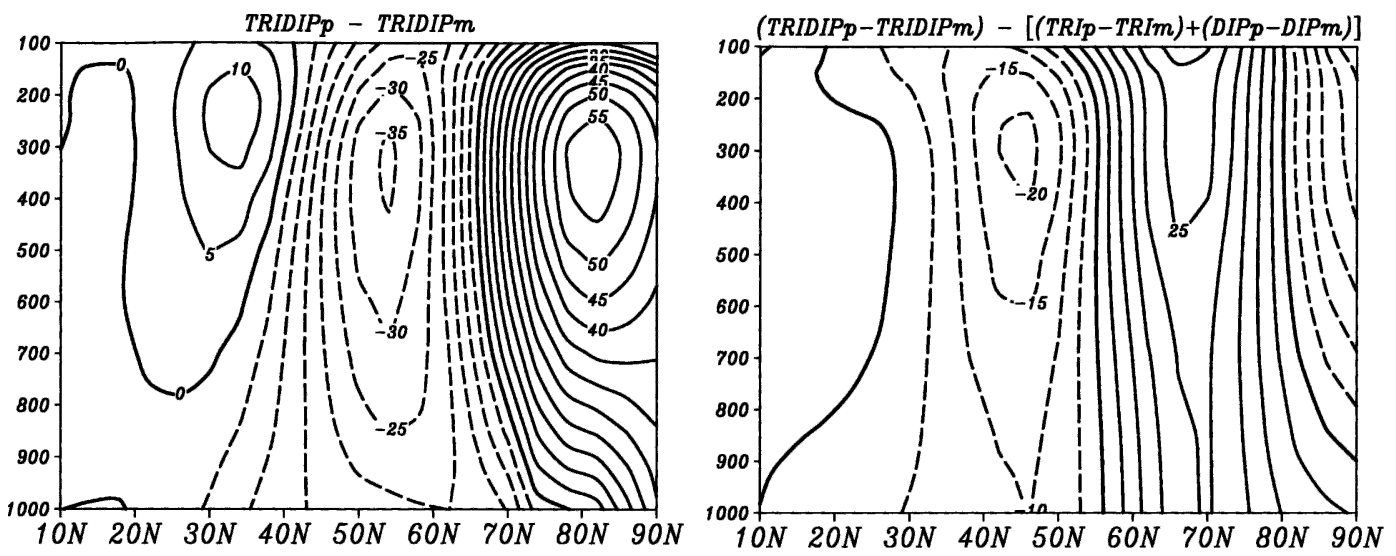

FIG. 11. Latitude-height cross section showing zonal mean $\left(90^{\circ} \mathrm{W}-30^{\circ} \mathrm{E}\right)$ winter (left) geopotential height response and (right) difference with the linear responses $(\mathrm{m})$.

the North Pole. The maximum response is obtained around $300 \mathrm{hPa}$ where the sign of the temperature response changes. In the tropical and subtropical regions, the geopotential response is weaker partly because of the Coriolis effect, but also because our model is less sensitive to tropical and subtropical forcings. The geopotential height response is somehow baroclinic in the Tropics.

The vertical structure of the geopotential height response in the combined TRIDIP experiment closely resembles the SST tripole response (the spatial correlation is 0.75). It seems that the structure of the total geopotential response is shaped by the SST forcing. It is shifted to the south by the effects of the SIC forcing and by the nonlinear interactions between the two individual responses (see right panel in Fig. 11). The amplitude of the positive (negative) center around $85^{\circ} \mathrm{N}$ $\left(60^{\circ} \mathrm{N}\right)$ increases (decreases) under the influence of the SIC forcing and the nonlinearities.

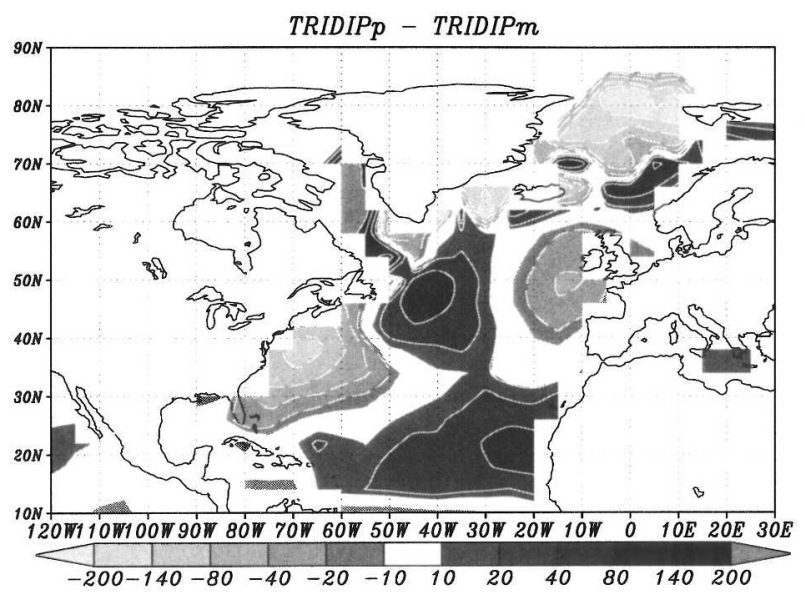

The effects of the combined oceanic forcings on the net surface heat flux and on the precipitation are shown in Fig. 12. As described in the previous section the heat fluxes are very sensitive to the surface perturbations, in particular, in the high latitudes over the sea ice regions.

The combination of the individual SST and SIC forcings is mainly linear for the heat flux and the precipitation. In the low and midlatitudes the tripolar SST forcing play the dominant role while in the high latitudes it is the dipolar effect that is induced by the sea ice increase/decrease. In the region of increased (decreased) SST, the surface heat flux anomaly tends to warm (cool) the air mainly through changes in the evaporation rate. The evaporation changes are almost completely balanced by precipitation changes. Over the retreat (extension) of the sea ice, the evaporation increases (decreases) leading to an increase (decrease) of the rainfall. As in Alexander et al. (2004), most of the

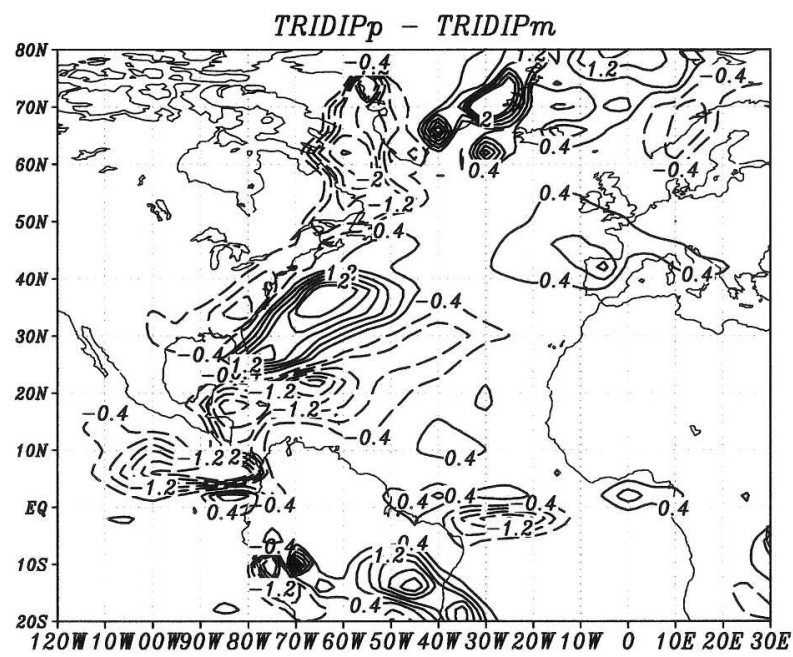

FIG. 12. (left) Net surface heat flux and (right) precipitation total symmetric responses in the TRIDIP experiment in winter (DJF). (left) Units: $\mathrm{W} \mathrm{m}^{-2}$ and the contours shown are $-200,-140,-80,-40,-20,-10,10,20,40,80,140$, are $200 \mathrm{~W} \mathrm{~m}^{-2}$. Positive heat flux anomalies correspond to a warming tendancy of the air above the surface; (right) $\mathrm{mm} \mathrm{day}^{-1}$, and the contour intervals are $0.4 \mathrm{~mm} \mathrm{day}^{-1}$. 


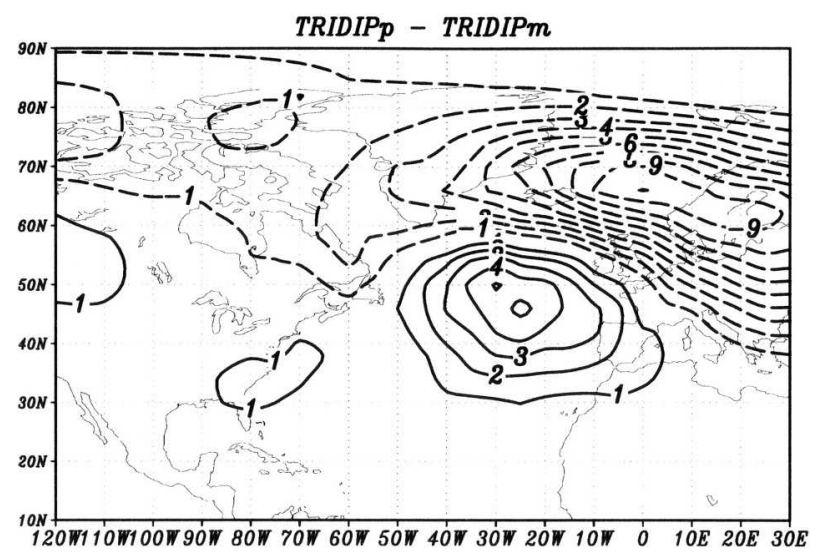

FIG. 13. Storm tracks (std dev of bandpass-filtered daily $Z_{500}$ ) symmetric response in the TRIDIP experiment in winter $(\mathrm{m})$.

evaporation $(75 \%)$ anomalies are compensated by local precipitation anomalies, mainly due to changes in convective activity. The precipitation response is maintained simultaneously by this direct local effect of the surface temperature and evaporation changes but also by the dynamical transient changes.

The modification of the oceanic boundaries induces a southward shift of the mean storm tracks and a slight reduction of its intensity (see right panel in Fig. 13). Both effects contribute to the precipitation anomalies but also to the temperature changes because the meridional heat transport due to transient eddies is also shifted and slightly reduced. Such storm track changes are able to maintain anomalies of the transient heat and vorticity fluxes (not shown). The modification of the transient eddy characteristics can in turn affect the large-scale circulation. Peng et al. (2003) presented a scenario explaining the different mechanisms maintaining the stationary response. They suggest that the symmetric stationary response results from the interaction between the heating-induced anomalous flow and the storm tracks.

Important changes of the storm tracks have been revealed in our experiments. Such complex mechanisms potentially contribute to the maintenance of the stationary response. More detailed analysis should be carried out in order to precisely describe the relevant dynamics.

\section{Asymmetry of the response about the sign of the forcing}

In this section, we will characterize the asymmetry of the response near the sign of the forcing, in the three different experiments: TRI, DIP, and TRIDIP. This asymmetry also manifests the nonlinearity of the atmospheric response (Peng et al. 2003).

The $T_{850}$ response relative to the control in the three experiments is shown in Fig. 14. We can see that the impacts of the oceanic changes on the lower-tropo- spheric temperature are highly significant in the vicinity of the forcings. The temperature response in the lower troposphere is mainly symmetric about the sign of the forcing in the two individual TRI (lower panels) and DIP (middle panels) experiments, and also in the combined TRIDIP experiment (upper panels).

We have computed the spatial correlation of the temperature responses to the positive and negative forcings, at four different levels $(1000,850,500$, and 250 $\mathrm{hPa})$. The correlation stands between -0.4 and -0.6 in the three experiments. The correlations are slightly higher in the individual experiments and in the lower troposphere $(850 \mathrm{hPa})$. We have already shown that the combination of the two individual forcings is almost linear for the temperature. As the temperature is responding linearly to the two separated SST and SIC forcings, it is natural that the combined temperature response should also be mainly linear.

Figure 15 presents the nonlinear $Z_{500}$ response relative to the control in the three experiments. In a general manner, the asymmetry of the response is large, comparable to the symmetric part of the response (not shown). The responses to the negative phase of the sea ice dipole (middle-right panel) and the SST tripole (lower-right panel) are stronger than that to the positive phase forcings (middle- and lower-left panels). In contrast to the responses of the individual forcings, the response to the positive combined forcings (upper-left panel) is stronger than the response to the negative forcings (upper-right panel). Peng et al. (1995) show some evidence of a stronger sensitivity of their model to a warm midlatitude SST. Their atmospheric response to a cold midlatitude SST forcing was weak and insignificant. On the other hand, using a different and much larger extratropical forcing and a different model, Magnusdottir et al. (2004) present some evidence that their simulated response is nonlinear in the polarity of the forcing but linear in the amplitude of the forcing. Kucharski and Molteni (2003) also showed that the simulated response of their simplified GCM to the SST tripole is nonlinear in the sign of the forcing. They suggest along with Deser et al. (2004) that the asymmetries in the heating anomalies induced by the SST forcing are the main reason for these nonlinearities. Examination of the heating profile (not shown) in our experiments seems to confirm this explanation.

Additional analysis of the transient response shows that the stationary response results from a subtle equilibrium between a direct thermal response, which dominates the initial response, and is followed by an indirect dynamical response that significantly modifies the initial thermal response ( $\mathrm{Li}$ and Conil 2003b). Peng et al. (2003) revealed that the indirect dynamical response is 

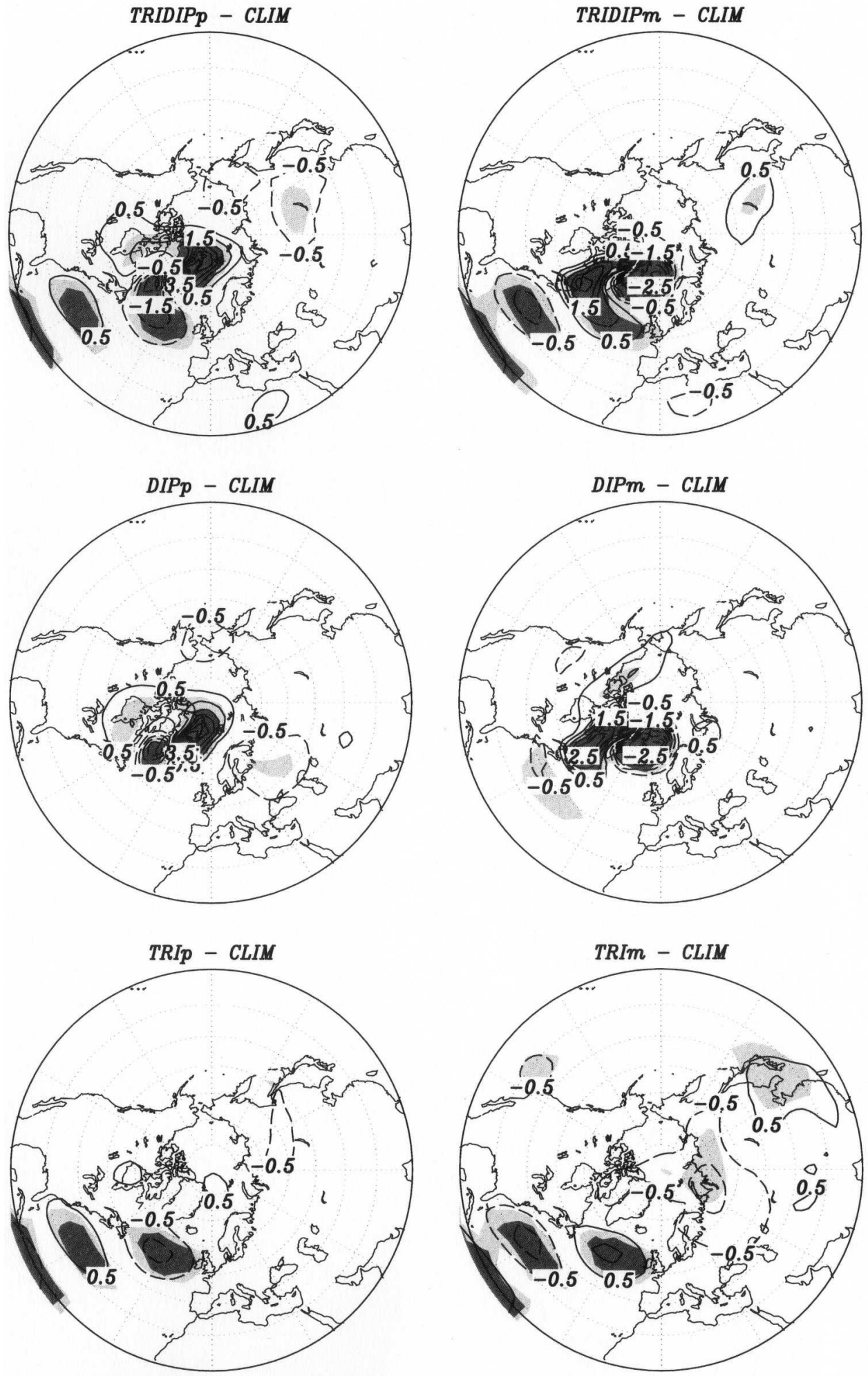

FIG. 14. Temperature response at $850 \mathrm{hPa}$ in winter (DJF): (upper) TRIDIP, (middle) DIP, and (lower) TRI. Contour intervals are $0.5^{\circ} \mathrm{C}$ and one of every two contours is labeled. The light (dark) gray shaded regions show the $90 \%(99 \%)$ significance level of the response according to a standard $t$ test. 

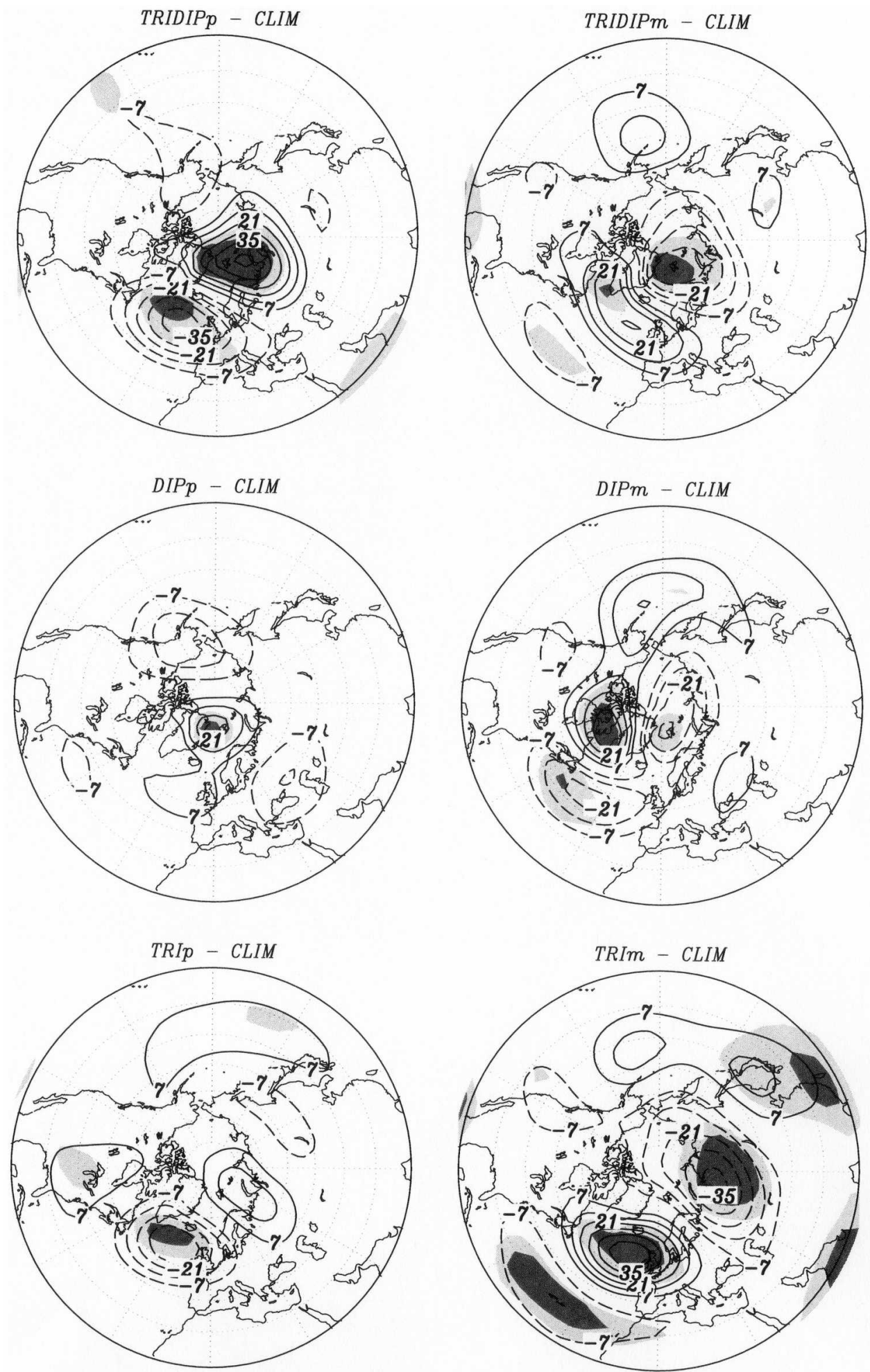

FIG. 15. Geopotential height response at $500 \mathrm{hPa}$ in winter (DJF): (upper) TRIDIP, (middle) DIP, and (lower) TRI. Contour intervals are $7 \mathrm{~m}$ and one of every two contours is labeled. The light (dark) gray shaded regions show the $90 \%(99 \%)$ significance level of the response according to a standard $t$ test. 
mainly controlled by nonlinear interactions between the transients and the direct thermal response. Our simulations suggest that the low-level temperature response is dominated by the direct thermal response. On the other hand, the upper-level temperature and geopotential height responses are formed by nonlinear combinations of the direct and indirect components.

Deser et al. (2004) present a decomposition of the total geopotential height response to SST and SIC forcings into direct and indirect parts. The decomposition shows that, for the geopotential height from upper to lower levels, both the direct and indirect parts play a significant role in the maintenance of the total response. But the decomposition of the temperature response was not presented. Our results suggest that the direct response must prevail for temperature, especially in the lower levels of the atmosphere.

\section{Concluding remarks}

In this study, we have investigated the sensitivity of an atmospheric GCM, the LMDZ, to anomalies of the extratropical oceanic boundary conditions. Both SST and SIC anomalies in the North Atlantic were used. Such simulations are designed and analyzed in order to estimate the potential feedback of the oceanic surface conditions back onto the atmosphere in a perfect model context.

We have defined typical patterns of North Atlantic SST and SIC anomalies associated with the positive and negative phase of the NAO. These patterns are also very similar to the first mode of interannual-decadal variability of the SST and SIC. They are defined for each month of the calendar year in order to have a realistic seasonal cycle of the forcing. We performed then three main numerical experiments (six simulations) in which 1) the addition/subtraction of the tripolar SST anomalies to the climatological SST, 2) the addition/ subtraction of the dipolar SIC anomalies to the climatological SIC distribution, and 3) the addition/subtraction of both the tripolar SST and dipolar SIC anomalies to the climatological oceanic surface conditions were used as lower boundary conditions for the AGCM. The design of our experiments permits us to evaluate the individual and combined effects of SST and SIC anomalies. The SIC anomalies are realistic, while the SST anomalies are scaled to have a maximum amplitude of $2^{\circ}$ in order to obtain a more robust atmospheric response. For each experiment, two 50-yr integrations are performed. The atmospheric response is defined with respect to a long "control" simulation of $150 \mathrm{yr}$ with climatological oceanic boundary conditions. The response of our model depends on the season, with the strongest signal in winter and spring. The explanation of this seasonal dependence is certainly related to the ampli- tude of the forcing itself and the model internal dynamics, as evidenced in Peng et al. (1997). In this paper, we focused on the winter atmospheric response and detailed its linearity. The following conclusions can be drawn.

Our experiments show that the atmospheric circulation, at least in the LMDZ GCM, is sensitive to the modifications of the surface boundary conditions at the oceanic surface. This result is coherent with previous ones as described in Kushnir et al. (2002), Czaja and Frankignoul (2002), and Deser et al. (2000). Given the fact that both tripolar SST anomalies and dipolar SIC anomalies in the North Atlantic have been connected to atmospheric forcing, especially the NAO (Cayan 1992; Seager et al. 2000; Deser et al. 2000), considerable feedbacks are plausible in the North Atlantic sector through the interplay of the atmosphere, ocean, and sea ice.

The atmospheric temperature response is mainly symmetric to the sign of the forcing and linear to the combination of SST and SIC forcing. The symmetric part of the temperature response in the two experiments is clearly dominant. The combination of the two forcings is mainly linear for the temperature, at least in the lower and midtroposphere. Most of the significant temperature response is located in the forcing regions for all the three experiments. The SIC forcing maintains a baroclinic response with a strong temperature anomaly in the lower troposphere in the forcing region, but with a very weak vertical penetration. The temperature response to the SST forcing is also much stronger near the surface, but it extends through the entire troposphere. In fact the SST anomalies maintain a mostly equivalent barotropic response.

The geopotential height response in the two separated forcing experiments is of the same order (the DIP experiment being slighly weaker). But their simulated spatial structures are completely different with a more locally confined response for the SIC dipole. In contrast with the temperature, the geopotential height response has an important asymmetric component. The geopotential height responses to the negative phase of the SST and SIC forcings are stronger than those to the positive phase. This is in agreement with Magnusdottir et al. (2004) showing that the simulated atmospheric circulation is more sensitive to the negative phase of the extratropical part of the SST tripole. In our TRIDIP experiment, the geopotential is more sensitive to the positive phase of the combined forcing. The combination of the two SST and SIC forcings is mainly nonlinear for the geopotential height. The nonlinearity between SST and SIC seems to shift the atmospheric response to the south. It is clear that the SST forcing dominates the total response, but the SIC influence is nonnegligable and should be taken into consideration. 


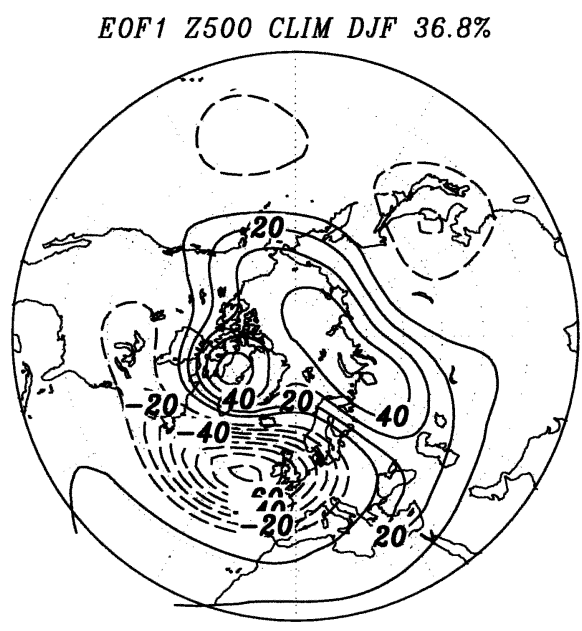

FIG. A1. First EOF of the winter Northern Hemisphere 500-hPa geopotential height anomalies in the CLIM experiment $(36.8 \%$ of the variance). Contour intervals are $10 \mathrm{~m}$ and one of every two contours is labeled.

The SST anomalies have strong impacts on precipitation in the North Atlantic and also in the tropical Atlantic. These precipitation anomalies and the associated largescale circulation changes may, in turn, influence the extratropical regions, as revealed by Sutton et al. (2001) and Kucharski and Molteni (2003). Such influences through the tropical-extratropical interactions are weak in our model. The effects of the SIC anomalies on precipitation are mainly restricted to the extratropical regions.

Finally, our simulations also reveal important modifications of the storm tracks and of the transient properties of the atmosphere. It is now clear that the transients play a key role in the maintenance of the atmospheric reponse in atmospheric GCM experiments, as presented in Peng and Robinson (2001) and Peng et al. (2003). In the future it will be certainly interesting to study in more detail the dynamical properties of the response, and to quantify the relative importance of extratropical transient versus tropical forcings. This should help us to firther understand the difference between the SST and SIC impacts and how they combine.

Acknowledgments. The authors thank B. Khan for his careful reading of the manuscript. We would also like to express our appreciation to two anonymous reviewers for their many useful and encouraging comments on the original manuscript. Computer resources were allocated by IDRIS, the computer center of the CNRS.

\section{APPENDIX}

\section{Dominant Mode of Internal Variability}

A large part of the northern extratropical atmospheric variability is controlled by internal dynamical processes. Furthermore, it has been recently suggested that the internal modes of variability and the mean circulation contribute dominantly to the maintenance of the atmospheric response to extratropical oceanic forcing (Peng et al. 2002; Deser et al. 2004). This, we calculate the leading mode of our model's internal variability by using an EOF analysis of the 500-hPa geopotential height. We use the winter seasonal mean of the CLIM experiment to perform the analysis. The EOF analysis was carried out over the Northern Hemisphere from $22^{\circ}$ to $90^{\circ} \mathrm{N}$ using the temporal covariance matrix. The anomalies were weighted by the square root of the cosine of latitude to convert the data to a nearly equal area grid. The dominant mode is plotted in Fig. A1 in terms of hemispheric maps of $500-\mathrm{hPa}$ geopotential height regressed onto the amplitude time series of the leading EOF. This mode captures nearly $37 \%$ of the hemispheric variance and is well separated from the second EOF, which accounts for $15 \%$ of the variance. This pattern is not sensitive to the data treatment and was found using monthly anomalies (i.e., rotated EOF analysis). The simulated dominant mode clearly shares many characteristics with the observed North Atlantic Oscillation (NAO) or annular mode [the Atlantic Oscillation (AO)]. But it is still significantly different from the observed NAO and this likely has affected the forced responses considerably. The model's NAO/AO represents a realistic north-South dipole well marked over the North Atlantic basin but its centers of action are shifted to the north. A spectral analysis of the principal component revealed that the temporal behavior is dominated by interannual variations (2-5 yr) over decadal variations (7-12 yr).

\section{REFERENCES}

Alexander, M.-A., U.-S. Bhatt, J.-E. Walsh, M.-S. Timlin, J.-S. Miller, and J.-D. Scott, 2004: The atmospheric response to realistic Arctic sea ice anomalies in an AGCM. Part I: Winter. J. Climate, 17, 890-905.

Barsugli, J.-J., and D.-S. Battisti, 1998: The basic effects of atmosphere-ocean thermal coupling on midlatitude variability. $J$. Atmos. Sci., 55, 477-493.

Cassou, C., 2001: Rôle de l'océan dans la variabilité basse fréquence de l'atmosphère sur la région Atlantique NordEurope. Thèse de doctorat, Université Paul Sabatier, 280 pp.

Cayan, D.-R., 1992: Latent and sensible heat flux anomalies over the northern oceans: The connection to monthly atmospheric circulation. J. Climate, 5, 354-369.

Conil, S., and Z.-X. Li, 2003: Influence of the North Atlantic Ocean on the simulated atmospheric variability. Ann. Geophys., 46, 57-70.

Czaja, A., and C. Frankignoul, 2002: Observed impact of Atlantic SST on the North Atlantic Oscillation. J. Climate, 15, 606-623.

Da Costa, E., and A. Colin de Verdiere, 2002: The 7.7-year North Atlantic Oscillation. Quart. J. Roy. Meteor. Soc., 128, 797-818.

Deser, C., and M.-L. Blackmon, 1993: Surface climate variations over the North Atlantic Ocean during winter: 1900-1989. J. Climate, 6, 1743-1753.

, J.-E. Walsh, and M.-S. Timlin, 2000: Arctic sea ice variability in the context of recent atmospheric circulation trends. $J$. Climate, 13, 617-633. 
_- M. Holand, G. Reverdin, and M.-S. Timlin, 2002: Decadal variations in Labrador sea ice cover and North Atlantic sea surface temperatures. J. Geophys. Res., 107, 3035, doi:10.1029/ 2000JC000683.

—, G. Magnusdottir, R. Saravanan, and P. Phillips, 2004: The effects of North Atlantic SST and sea ice anomalies on the winter circulation in CCM3. Part II: Direct and indirect components of the response. J. Climate, 17, 877-889.

Fouquart, Y., and B. Bonnel, 1980: Computations of solar heating of the earth's atmosphere: A new parameterization. Beitr. Phys. Atmos., 53, 35-52.

Frankignoul, C., 1985: Sea surface temperature anomalies, planetary waves and air sea feedbacks in the middle latitudes. Rev. Geophys., 23, 357-390.

Hoerling, M.-P., J.-W. Hurrel, and T. Xu, 2001: Tropical origins for recent North Atlantic climate change. Science, 292, 90-92.

Hudson, D.-A., and B.-C. Hewitson, 2001: The atmospheric response to a reduction in summer Antarctic sea-ice extent. Climate Res., 16, 79-99.

Hurrel, J.-W., 1996: Influence of variations in extratropical wintertime teleconnections on Northern Hemisphere temperature. Geophys. Res. Lett., 23, 665-668.

—, M.-P. Hoerling, A. Phillips, and T. Xu, 2004: Twentieth century North Atlantic climate change. Part I: Assessing determinism. Climate Dyn., 23, 371-389.

Kucharski, F., and F. Molteni, 2003: On non-linearities in a forced North Atlantic Oscillation. Climate Dyn., 21, 677-687.

Kushnir, Y., and I.-M. Held, 1996: Equilibrium atmospheric response to North Atlantic SST anomalies. J. Climate, 9, 1208-1220.

_ , W.-A. Robinson, I. Bladé, N.-M. Hall, S. Peng, and R. Sutton, 2002: Atmospheric GCM response to extratropical SST anomalies: Synthesis and evaluation. J. Climate, 15, 2233-2256.

Latif, M., K. Arpe, and E. Roeckner, 2000: Oceanic control of decadal North Atlantic sea level pressure variability in winter. Geophys. Res. Lett., 27, 727-730.

Le Treut, H., and Z.-X. Li, 1991: Sensitivity of an atmospheric general circulation model to prescribed SST changes: Feedback effects associated with the simulation of cloud properties. Climate Dyn., 5, 175-187.

Li, Z.-X., and S. Conil, 2003a: A 1000-year simulation with the IPSL ocean-atmosphere coupled model. Ann. Geophys., 46, 39-46.

$\longrightarrow$, and - 2003b: Transient response of an atmospheric GCM to North Atlantic SST anomalies. J. Climate, 16, 3993-3998.

Lunkeit, F., and Y. von Detten, 1997: The linearity of the atmospheric response to North Atlantic sea surface temperature anomalies. J. Climate, 10, 3003-3014.

Magnusdottir, G., C. Deser, and R. Saravanan, 2004: The effects of North Atlantic SST and sea ice anomalies on the winter circulation in CCM3. Part I: Main features and storm track characteristics of the response. J. Climate, 17, 857-876.

Mehta, V.-M., M.-J. Suarez, J.-V. Manganello, and T.-L. Delworth, 2000: Oceanic influence on the North Atlantic Oscillation and associated Northern Hemisphere climate variations. Geophys. Res. Lett., 27, 121-124.

Menendez, C., V. Serafini, and H. Le Treut, 1999: The effect of Sea Ice on the transient atmospheric eddies of the Southern Hemisphere. Climate Dyn., 15, 659-671.

Morcrette, J.-J., 1991: Radiation and cloud radiative properties in the ECMWF operational weather forecast model. J. Geophys. Res., 96D, 9121-9132.

Murray, R.-J., and I. Simmonds, 1995: Responses of climate and cyclones to reductions in Arctic winter sea ice. J. Geophys. Res., 100, 4791-4806.
Palmer, T.-N., and Z. Sun, 1985: A modelling and observational study of the relationship between SST in the North West Atlantic and the atmospheric general circulation. Quart. J. Roy. Meteor. Soc., 111, 947-975.

Peng, S., and W.-A. Robinson, 2001: Relationships between atmospheric internal variability and the responses to an extratropical SST. J. Climate, 14, 2943-2959.

_ L.-A. Mysak, H. Ritchie, J. Derome, and B. Dugas, 1995: The differences between early and midwinter atmospheric responses to sea surface temperature anomalies in the northwest Atlantic. J. Climate, 8, 137-157.

- W.-A. Robinson, and M.-P. Hoerling, 1997: The modeled atmospheric response of midlatitude SST anomalies and its dependence on background circulation states. J. Climate, 10, 971-987.

- — , and S. Li, 2002: North Atlantic SST forcing of the NAO and relationships with intrinsic hemispheric variability. Geophys. Res. Lett., 29, 1276, doi:10.1029/2001GL014043.

,-- , and 2003: Mechanism for the NAO response to the North Atlantic SST tripole. J. Climate, 16, 1987-2004.

Rodwell, M.-J., and C.-K. Folland, 2002: Atlantic air-sea interaction and seasonal predictability. Quart. J. Roy. Meteor. Soc., 128, 1413-1444.

— D.-P. Rowell, and C.-K. Folland, 1999: Oceanic forcing of the wintertime North Atlantic Oscillation and European climate. Nature, 398, 320-323.

Sadourny, R., 1975: The dynamics of finite difference models of the shallow water equations. J. Atmos. Sci., 32, 680-689.

- and K. Laval, 1984: January and July performance of the LMD general circulation model. New Perspectives in Climate Modelling, A. Berger and C. Nicolis, Eds., Elsevier Science Publishers, 173-198.

Schneider, E.-K., L. Bengtsson, and Z.-Z. Hu, 2003: Forcing of Northern Hemisphere trends. J. Atmos. Sci., 60, 1504-1521.

Seager, R.-Y., V.-M. Kushnir, N. Naik, J. Miller, G. Krahmann, and H. Cullen, 2000: Causes of Atlantic Ocean climate variability between 1958 and 1998. J. Climate, 13, 2845-2862.

Simmonds, I., and W.-F. Budd, 1991: Sensitivity of the southern hemisphere circulation to leads in the Antarctic ice pack. Quart. J. Roy. Meteor. Soc., 117, 1003-1024.

Slonosky, V.-C., L.-A. Mysak, and J. Derome, 1997: Linking Arctic Sea Ice and atmospheric circulation anomalies on interannual to decadal timescales. Atmos.-Ocean, 35, 333-366.

Sutton, R.-T., and M.-R. Allen, 1997: Decadal predictability of North Atlantic sea surface temperature and climate. Nature, 388, 563-567.

— W.-A. Norton, and S.-P. Jewson, 2001: The North Atlantic Oscillation-What role for the ocean? Atmos. Sci. Lett., 1, 89-100.

Tiedke, M., 1989: A comprehensive mass flux scheme for cumulus parameterization in large-scale models. Mon. Wea. Rev., 117, 1779-1800.

Venegas, S.-A., and L.-A. Mysak, 2000: Is there a dominant timescale of natural climate variability in the Arctic? J. Climate, 13, 3412-3434.

Visbeck, M., E.-P. Chassignet, R.-G. Curry, T.-L. Delworth, R.-R. Dickson, and G. Krahmann, 2003: The Ocean's response to North Atlantic Oscillation variability. The North Atlantic Oscillation: Climatic Significance and Environmental Impact, Geophys. Monogr., No. 134, Amer. Geophys. Union, 113-146.

Wallace, J.-M., C. Smith, and Q. Jiang, 1990: Spatial patterns of atmosphere ocean interactions in the northern winter. J. Climate, 3, 990-998.

Watanabe, M., and M. Kimoto, 2000: On the persistence of decadal SST anomalies in the North Atlantic. J. Climate, 13, 3017-3028. 